\title{
Los principios generales del derecho en el artículo 230 de la Constitución Política. ¿Normas morales o normas jurídicas?*
}

\author{
Sergio Estrada Vélez** \\ Recibido: mayo de 2016 \\ Aprobado: agosto de 2016 \\ DOI: 10.22395/ojum.v15n30a2
}

\section{RESUMEN}

Pasados veinticinco años, pervive la falta de legitimidad en la Administración de Justicia, lo que exige indagar por las razones y proponer soluciones. Una de ellas es el artículo 230, cuyo texto parece evocar el razonamiento jurídico del siglo XIX. La enunciación de principios como criterios auxiliares parece oponerse a un razonamiento jurídico que reivindica su prevalencia sobre las restantes normas del ordenamiento. De allí el temor al prevaricato en los operadores jurisdiccionales al momento de su aplicación. Esa interpretación está alimentada por el sentido otorgado a la expresión "principios generales del derecho" como normas que están por fuera del ordenamiento jurídico, realizada en la sentencia C-083 de 1995. Por ello, es necesario abordar su estudio a partir de tres aspectos: los cambios en el razonamiento jurídico exigidos por el Estado social de derecho colombiano, el análisis de las fuentes bibliográficas empleadas en la sentencia y su coherencia con otras normas del ordenamiento. El principal hallazgo es la necesidad de una reinterpretación del artículo 230 a la luz de la naturaleza y funciones de los principios en el Estado social de derecho colombiano.

Palabras clave: principios jurídicos; principios generales del derecho: reglas generales del derecho; principios morales.

\footnotetext{
El presente artículo es resultado de los procesos de investigación del grupo Auditorio Constitucional, perteneciente a la Facultad de Derecho de la Institución Universitaria de Envigado.

* Profesor de Teoría del Derecho, Principialística y Hermenéutica Jurídica de la Facultad de Derecho de la Institución Universitaria de Envigado, investigador del grupo Auditorio Constitucional, perteneciente a la misma institución; especialista en derecho constitucional; especialista en argumentación jurídica; Diploma de Estudios Avanzados Universidad de León (España); magíster en Derecho; estudios de doctorado Universidad de Buenos Aires; Director del Centro de Estudios Políticos y Constitucionales de Medellín; autor de los textos: La excepción de principialidad (ed. Temis 2000), Los principios jurídicos y el bloque de constitucionalidad (Ed. Universidad de Medellín, 3.a ed. 2011).correo: estradav72@hotmail.com.
} 


\title{
General Principles of Law Contemplated in Article 230 of the Political Constitution. Moral or Legal Norms?
}

\begin{abstract}
Lack of legitimacy in Justice Administration is still noticed after 25 years; this demands a deeper investigation on the reasons and a proposal of solutions. One of the solutions involves Article 230, which text seems to evocate the legal reasoning of the 19th century. The declaration of principles as ancillary criteria seems to be opposed to a legal reasoning which claims its prevalence on remaining norms of the legal system. For this reason, there is a fear to the breach of public duties by jurisdictional officers at the time of relevant application. Such interpretation has been based on the sense given to the expression "general principles of law" as norms that are out of the legal system, as contemplated in Sentence C-083 of 1995. It is then necessary to address its study from three aspects: changes of legal reasoning demanded by the Colombian social rule-of-law state; the analysis of bibliographic sources employed in the sentence; and consistency with other norms of the legal system. The main finding is the need for a new interpretation of Article 230 in the light of nature and functions of the principles in the Colombian social rule-of-law state.
\end{abstract}

Key words: legal principles; general law principles; general law rules; moral principles. 


\section{INTRODUCCIÓN}

Quienes asumen el estudio y enseñanza de la teoría del derecho en Colombia han olvidado el análisis referido a las transformaciones que ha tenido con la incorporación del Estado social. Los cambios, aún por descubrirl, han sido en aspectos fundamentales como la noción de norma, ordenamiento y fuentes del derecho. En la actualidad se percibe un modelo de enseñanza del derecho anclado en la racionalidad lógico-jurídica de finales del siglo XIX a causa, parece ser, del temor a incursionar en un razonamiento acorde al logos de lo humano que procure por el logro de una justicia material, por la humanización del derecho.

La noción principios generales del derecho (en adelante PGD) ha sufrido una profunda metamorfosis aún inadvertida por los cultores de la ciencia del derecho. Se ha transitado de la idea de principios como normas morales, extra-sistemáticas o subsidiarias, a la noción de principios como principales normas del ordena-

\footnotetext{
Con el ingreso del Estado social, la teoría del derecho ha debido vivir una época de oro, pero la oportunidad de superar viejos paradigmas se ha echado por la borda. Se requiere una teoría del derecho que ayude a la superación de las fricciones entre perspectivas idealistas, pragmáticas y formalistas del derecho. Pertinentes las palabras de Ferrajoli: "La teoría del derecho, y en especial del estado constitucional de derecho, con las divergencias que comporta entre principios éticopolíticos, principios de derecho y práctica jurídica, puede postularse como el lugar en el que es posible recomponer las diferentes fracturas disciplinarias (entre ciencia del derecho, sociología y filosofía) que han marcado la historia de la cultura jurídica moderna". La teoría del derecho en el sistema de los saberes jurídicos" (2008, pp. 66,67).
}

miento jurídico de las que se desprenden estas funciones principales: fundamento de derechos fundamentales, criterios de validez material de las restantes normas, medios de concreción de los valores, principales herramientas para la legitimación racional del poder del Estado y razones para la decisión en las sentencias de las altas cortes.

Esas importantes funciones son consecuencia de causas externas como el constitucionalismo de posguerra (o neoconstitucionalismo), e internas como la voluntad de nuestro constituyente de hacer de los principios límites de hierro al ejercicio del poder, la tendencia del legislador de enunciar en importantes leyes un conjunto de principios a los que les dota del carácter de normas prevalentes, el reconocimiento de ellos como criterios de casación ${ }^{2}$ y la importancia "excepcional" que adquieren en el Estado social, según la sentencia T-406 de 1992. Todas ellas permiten señalar que no se pueden considerar normas extra-sistemáticas o subsidiarias.

A pesar de la claridad del constituyente, del legislador, de la jurisprudencia de la Corte Suprema de Justicia y de la Corte Constitucional al afirmar la importancia de los principios generales del derecho,

\footnotetext{
Corte Suprema de Justicia, octubre 7 de 2009, exp. 05360-31-03-001-2003-00164-01. M. P. Edgardo Villamil Portilla. Allí se indicó: "Las referidas circunstancias, aunadas al conjunto nutrido de fallos en que la Corte desarrolló los principios generales del derecho, dejan ver nítidamente que ellos como parte fundamental del ordenamiento jurídico pueden operar y, de hecho, se han admitido como norma de derecho sustancial cuya violación es susceptible de ser acusada a través del recurso de casación".
} 
se advierte que en la sentencia C-083 de 1995 M. P. Carlos Gaviria Díaz se afirma que son normas de derecho natural o extra-sistemáticas, siendo al día de hoy uno de los principales obstáculos al desarrollo de una cultura principial acorde con el Estado social de derecho. ¿Por qué abordar su estudio a veinte años de su expedición? La respuesta es simple: porque, a pesar de los cambios normativos y la existencia de razones que explican con claridad la idea de principios como normas prevalentes, se advierte en la práctica jurídica una profunda reticencia a su aplicación por temor al prevaricato ${ }^{3}$ en la medida que los servidores públicos los consideran, con fundamento en esa sentencia, normas extra-sistemáticas.

La sentencia C-083 de 1995 no solo se ha constituido en uno de los más fuertes obstáculos para el desarrollo de una teoría principial coherente con el razonamiento jurídico que impone el Estado social de derecho, sino que, además, ha alimentado la actual crisis de la Administración de Justicia en la medida que promueve un razonamiento judicial ajeno al Estado social de derecho. En virtud de ello, se tiene como principales objetivos del presente escrito analizar la argumentación empleada en esa sentencia frente a los principios generales del derecho, advertir la necesidad de más y mejores estudios dedicados a la principialística jurídica que ayuden a la determinación de su naturaleza y funciones dentro del

3 En desarrollo de investigación adelantada en el año 2008, se advirtió que el 31\% de los jueces encuestados (de una muestra de 133) manifestaron su temor al prevaricato al momento de aplicar un principio general del derecho. contexto del Estado social de derecho colombiano, aportar al fortalecimiento del razonamiento jurídico y promover la enseñanza de la materia.

\section{ACLARACIÓN EPISTEMOLÓGICA}

Una de las principales tareas de quienes asumen el estudio de la teoría del derecho es la de identificar, a la luz de un contexto político y social determinado, los rasgos principales del razonamiento jurídico ${ }^{4}$. Precisamente, el desarrollo de una epistemología jurídica al margen de cada realidad social ha llevado, en nombre de una noción dogmatizante de ciencia del derecho con pretensiones de logicidad, universalidad e inmutabilidad, a proponer una idea de derecho ajena a las necesidades sociales.

A lo anterior se suma la ausencia de mínimos consensos teóricos acerca de los conceptos básicos que deben estructurar una teoría jurídica en el contexto del Estado social de derecho. Ello ha promovido que en las aulas se replique una idea de derecho que perpetúa conceptos elaborados en el marco de la racionalidad dirigidos a la protección de una idea de seguridad jurídica propia del siglo XIX, al margen de la razonabilidad o logos de lo humano y la búsqueda de una justicia material. Un ejemplo de lo anterior es la idea de principios generales del derecho que no cuenta con mínimos acuerdos en relación con su naturaleza y con sus funciones.

Entendido este como las características que describen la forma de pensar el derecho en sus diferentes momentos de creación, interpretación y aplicación. 
Es necesario hacer una aclaración lingüística: la expresión "principios generales del derecho" es polisémica, y en atención a la presencia de varios significados, se comprende la existencia de diferentes perspectivas desde las cuales se pretende abordar su estudio, siendo las más importantes el iusnaturalismo y el iuspositivismo. Aquel afirmará que son normas morales ubicadas fuera del ordenamiento jurídico; este señalará, básicamente, que son normas jurídicas que pertenecen al ordenamiento, pero cuya función es auxiliar a la ley. Ambas nociones dejan al intérprete la compleja misión de determinar el sentido al momento de su aplicación, para lo cual utilizan criterios que, en ocasiones, emulan la conveniencia. En medio de una clara tendencia al reconocimiento de un pluralismo epistemológico ${ }^{5}$, resulta difícil continuar con la confrontación entre el iusnaturalismo y el iuspositivismo

\footnotetext{
Señala Habermas: "La tensión entre planteamientos normativistas, que siempre corren el riesgo de perder el contacto con la realidad social, y planteamientos objetivistas que eliminan todos los aspectos normativos, puede servir como advertencia para no empecinarse en ninguna orientación ligada a una sola disciplina, sino mantenerse abiertos a distintos puntos de vista epistemológicos" (p. 68). Igualmente critica el iusnaturalismo por el reduccionismo del derecho a la justicia, sólo lo que es justo es derecho, también critica al positivismo por reducir el derecho a la legalidad, por lo que es necesario una noción de derecho discursivo, argumentativo-racional, en la que la legitimidad sea el resultado de la participación de todos, al menos los que puedan resultar afectados, en la configuración de las decisiones, bajo un discusión regida por ser abierta, igualitaria, soportada en argumentos racionales y en la búsqueda del consenso. Su propósito claramente lo expresa con estas palabras: "Lo que en este contexto me importa es la elaboración de un planteamiento reconstructivo que haga suyas ambas perspectivas: la de una teoría sociológica del derecho y la de una teoría filosófica de la justicia" (P. 69).
}

en relación con la fundamentación de los principios jurídicos ${ }^{6}$.

La elección de una u otra noción de principios, la iusnaturalista o la iuspositivista, se debe enmarcar dentro de las libertades políticas y jurídicas, esto es, no se puede sugerir una específica idea de principios en la medida que ambas desempeñan importantes funciones frente al derecho y en el derecho, por lo que es necesario señalar que son complementarias. Se propone demostrar que a la luz del Estado social de derecho es necesario reforzar o prestar mayor atención a una de las nociones de principios siguiendo para ello el camino trazado por los llamados estudios críticos del derecho que advierten la imposibilidad de comprenderlo a partir de perspectivas unidimensionales? ${ }^{7}$.

6 Al respecto, expresa Bidart Campos: "No entendemos demasiado la polémica entre iusnaturalistas y positivistas para enfatizar que los principios generales son de derecho natural o surgen del derecho positivo, porque una cosa es indagar su origen o fuente (si el derecho natural o positivo), y otra coincidir en que vengan de donde vinieren, pertenecen siempre a un orden jurídico positivo, o están dentro de él. Sería tanto como discutir si los derechos humanos tienen ascendencia en el derecho natural o nacen de derecho positivo; la cuestión, con ser importante, no implica negar, con cualquier posición, que cuando la constitución los declara, reconoce, o alberga, "están" en ella. Igual los principios generales". La interpretación y el control constitucionales en la Jurisdicción constitucional. Ed. Ediar, Buenos Aires, 1987, pág. 231.

7 Señala Chaim Perelman: "El razonamiento judicial, tal como actualmente se concibe, no permite establecer una distinción tan neta como la del siglo XIX entre derecho natural y derecho positivo. En efecto, si el derecho positivo es el derecho tal como funciona efectivamente en una situación dada, ya no coincide con los textos promulgados, pues, por una parte los principios generales y las reglas de derecho no escrito limitan o amplían el alcance de las disposiciones legislativas y, por 


\section{ACLARACIÓN SOCIO-JURÍDICA}

Un obstáculo al desarrollo de una teoría jurídica principial "a la colombiana" es el exagerado culto a una doctrina de derecho comparado que ha llevado a la incorporación, sin beneficio de inventario, de instituciones jurídicas o conceptos elaborados en contextos sociales y políticos distintos al nuestro. No puede ser igual una teoría de principios construida bajo el contexto europeo que una teoría de principios latinoamericana. El estudio de los principios jurídicos, como el de todas las fuentes del derecho, debe tener presente el contexto político y social. Se debe promover una teoría emancipadora de los principios jurídicos ${ }^{8}$. Reflexiones acerca de la legitimidad de los órganos con autoridad para crear normas jurídicas son fundamentales al momento de comprender la importancia de cada

otra, parte, hay textos legales que por una u otra razón dejan de aplicarse, por lo menos en toda su generalidad y, aunque formalmente válidos, ven su eficacia disminuida de una manera imprevisible.... En la actual concepción del derecho, menos formalista y más preocupada por la manera en que lo acepta el medio al que rige y por esto mismo interesada por conocer el modo de funcionar de la legislación dentro de la sociedad, es imposible identificar pura y simplemente el derecho positivo con el conjunto de las leyes y de los reglamentos votados y promulgados conforme a criterios que garantizan su validez formal, pues puede haber divergencias no desdeñables entre la letra de los textos, su interpretación y su aplicación. Cuando hablamos de la vida del derecho, nos referimos a la manera en que un mismo texto ha podido dar lugar a interpretaciones variables según las épocas." La lógica jurídica y la nueva retórica. Trad. Luis Díez-Picazo. Ed. Civitas, Madrid, 1. a ed. 1979. pp. 180 y 181.

8 Señala Antonio Carlos Walkmer: "Parece evidente que los cambios políticos y los nuevos procesos sociales de lucha en los Estados latinoamericanos, fuente dentro del ordenamiento jurídico y la relación entre las mismas.

Por ello, se puede afirmar que la mayor o menor importancia de los principios es directamente proporcional a la mayor o menor confianza que el titular del poder soberano, el pueblo, tenga en el legislador. Así, en contextos en los que existe un alto grado de legitimidad en la potestad de configuración normativa del legislador, como fiel representante de la voluntad popular, menor será la importancia de los principios y, en consecuencia, bastará con reconocerles una función auxiliar frente a la ley; por el contrario, mayor será su importancia en realidades en las que se evidencien altos niveles de desconfianza en el órgano legislativo, donde entran a ejercer una función de límite al ejercicio de la potestad de configuración del legislador (legitimidad racional) o fungir de criterios de validez material de las restantes normas del ordenamiento jurídico.

De esa manera, no es lo mismo hablar de principios en contextos en los que

no solo engendran nuevas constituciones que materializan nuevos actores sociales, realidades plurales y prácticas biocéntricas desafiadoras, sino que igualmente proponen, ante la diversidad de culturas minoritarias, de la fuerza indiscutible de los pueblos indígenas del Continente, de políticas de desarrollo sostenible y de la protección de bienes comunes naturales, un nuevo paradigma de constitucionalismo el cual podría denominarse Constitucionalismo Pluralista e Intercultural - síntesis de un Constitucionalismo indígena, autóctono y mestizo". Ese nuevo constitucionalismo y, por supuesto, la nueva teoría del derecho que le debe acompañar, exige una dogmática acorde a las necesidades sociales del pueblo latinoamericano (texto inédito). 
se evidencia una disciplina política en el órgano legislativo y una confianza en su función reguladora del interés general, que en aquellos en los que se advierte la necesidad de ejercer controles ante los riesgos de que infrinja no solo el principio representativo sino, también, la norma de normas. Si el Estado de derecho democrático tiene por una de sus principales tareas la limitación de toda expresión de poder a través de la norma jurídica, y la función legislativa es una actividad esencialmente política en la que, por demás, no se confía, es necesario fortalecer los mecanismos de control a la misma, a través de otras normas jurídicas que deben no solo limitar la actividad creadora de derecho, sino condicionar la validez de las normas derivadas de su actividad.

A modo de conclusión, poco beneficio prestará al fortalecimiento del razonamiento jurídico en el Estado social de derecho colombiano realizar un análisis de los principios jurídicos, de su naturaleza y funciones, con la ayuda única de textos escritos bajo realidades políticas y sociales totalmente diversas a las nuestras sin una labor de contextualización. Nuestra agreste realidad política ha permitido que en Colombia se desarrolle una de las más importantes propuestas en materia de principios que permite asumirlos como normas jurídicas y no morales, fundamento de los derechos fundamentales, prevalentes sobre las restantes normas del ordenamiento, concreción de los valores o fines del derecho, criterios de validez material y límites racionales al ejercicio del poder.

\section{LA NOCIÓN DE PRINCIPIOS JURIDICOS EN EL ESTADO SOCIAL Y CONSTITUCIONAL DE DERECHO}

El ingreso del Estado constitucional generó un mayor interés por el estudio de los principios jurídicos ${ }^{9} \mathrm{y}$ de sus relaciones con temas fundamentales de la teoría jurídica como las fuentes del derecho, la noción de validez material, el ordenamiento jurídico, norma jurídica, la interpretación, entre otros. Los principios pasan de ser considerados normas auxiliares a la ley, a criterios de constitucionalidad de la misma; fungen, junto a los derechos fundamentales, de principales criterios de validez material; ayudan a la consecución de la plenitud del ordenamiento jurídico; complementan el modelo de normas tipo regla $\mathrm{y}$, dada su naturaleza y funciones, son considerados normas pertenecientes al bloque de constitucionalidad.

Tan importante es la función de los principios en el Estado social que el constituyente los asumió como "límites de hierro" al ejercicio del poder ${ }^{10}$. Coherente con

\footnotetext{
En este sentido señala Bernal Pulido: "Una de las ideas más importantes de la teoría del derecho contemporánea, tanto en el mundo anglosajón como en el derecho continental, es que los ordenamientos jurídicos no están compuestos exclusivamente por reglas, es decir, por el tipo tradicional de normas jurídicas, sino también por principios" El derecho de los derechos. Universidad Externado de Colombia. Bogotá, 2005, p. 95. A su vez, indica Aragón Reyes: "...parece difícil negar que hoy el Derecho de la Constitución es un Derecho "por principios", esto es, que tenemos una Constitución principialista" El juez ordinario entre legalidad y constitucionalidad. Instituto de Estudios Constitucionales Carlos Restrepo Piedrahita, Bogotá, 1997, p. 23.

10 La confianza depositada en los principios se pone en evidencia cuando se expresa que son medios de contención de la arbitrariedad del poder del Estado, función que solo pueden cumplir los prin-
} 
ello y de manera paradójica, ha sido el mismo legislador el que ha reconocido la función limitadora de los principios, esto es, les reconoce el carácter de criterios de validez de las restantes normas de cada ordenamiento específico. Son normas que en virtud de su condición jurídica y prevalente en relación con la ley pueden ser incorporadas al bloque de constitucionalidad. Esa naturaleza y condición solo puede ser asignada a los principios jurídicos y no a los principios de derecho natural, esto es, a los principios expresamente reconocidos por el constituyente o el legislador (principios explícitos) o por el juez en ejercicio de la analogía iuris (principios implícitos) y no a los principios morales o extra sistemáticos.

Los principios, asumidos como normas jurídicas, no se limitan a cumplir una función interpretativa, integrativa y creativa. Asumen otras de igual o mayor importancia para la teoría política y la estimativa jurídica. Políticamente los principios limitan el ejercicio del poder, son criterios de legitimación racional del poder del Estado, expresión de la soberanía política del poder constituyente y fundamento de los derechos fundamentales. Desde

\footnotetext{
cipios cuando se asumen como normas jurídicas a las cuales debe supeditarse toda la actividad del Estado. Señala el constituyente Hernando Londoño Jiménez: (...) aspiramos a que se consagren normas constitucionales que en el futuro impidan este desbordamiento de las facultades al Ejecutivo con motivo del Estado de Sitio. Pero también, en previsión de que ello pueda ocurrir en el futuro, aspiramos a que se eleven a rango constitucional todos los principios, todos los derechos y garantías que en materia penal $y$ de procedimiento han sido abiertamente violados con la legislación de emergencia, como lo hacen las constituciones más modernas, las Cartas Fundamentales inspiradas en las corrientes liberales y democráticas del derecho contemporáneo (Londoño, 1991, p. 10).
}

la perspectiva axiológica, se puede afirmar que los principios son concreción o delimitación del contenido de los valores y, en esa medida, adquieren el rótulo de normas axiológico-deontológicas que comunican la moral con el derecho acercando este a la justicia material.

Los cambios en la teoría del derecho con el otorgamiento de mayor importancia a los principios en el Estado social coinciden con una tendencia en la doctrina del derecho comparado a reconocer en ellos normas jurídicas derivadas del ordenamiento jurídico, que determinan la validez de las restantes normas del ordenamiento, que fungen de criterios de legitimidad racional y fundamento de los derechos fundamentales ${ }^{11}$.

A pesar de las mutaciones de los contextos y de los textos, en Colombia persiste

11 Las siguientes citas demuestran la importancia de los principios. Marina Gascón Abellán, señala: "La proliferación de los principios en los textos constitucionales y el reconocimiento de su valor normativo han venido a transformar la idea misma sobre la Constitución y sobre los criterios de validez de las leyes" Fuentes del derecho. En Lecciones de teoría del derecho. Jerónimo Betegón Carrillo y otros. Madrid: McGraw-Hill, 1997. p.344. Häberle expresa que "Las reflexiones hechas hasta el momento sugieren, en el contexto de los enunciados textuales de las constituciones recientes, despedirse declaradamente del estatismo nacional de las doctrinas tradicionales sobre las fuentes del derecho...La penetración de la categoría de los "principios generales del derecho" quiebra el carácter estatal de las fuentes del derecho" HÄBERLE, Peter. El Estado constitucional. Trad. Héctor Fix Fierro. Buenos Aires: Astrea, 2007El Estado constitucional. p. 237.Guastini afirma que "los principios se caracterizan respecto a las (otras) normas porque desempeñan en el ordenamiento jurídico el papel de normas "fundamentales". Distinguiendo. Estudios de teoría y metateoría del derecho. Trad. Jordi Ferrer i Beltrán. Barcelona: Gedisa, 1999, p. 35. 
una concepción de principios como normas de derecho natural. Dos son los principales fundamentos: el artículo 4 de la Ley 153 de $1887^{12}$ y la sentencia C-083 de 1995 en la que se define el sentido de la expresión "principios generales del derecho", establecida en el artículo 230 de la Constitución Política. Esta decisión se erige en uno de los más fuertes obstáculos para el desarrollo de una teoría de principios acorde con el Estado social, razón por la cual se estima necesario su análisis.

En síntesis, se puede afirmar que en el Estado social y constitucional tienen especial importancia los principios jurídicos a punto que sirven, estén o no en el texto de la Constitución, como parámetros de constitucionalidad. De esta manera, es posible comprender cómo la teoría de las fuentes del derecho sufre una importante transformación en la medida que incorpora los principios como elementos que condicionan la validez de la ley y fungen de principal razón de la decisión en las sentencias de las altas cortes.

\section{LOS PRINCIPIOS GENERALES DEL DERECHO ¿NORMAS EXTRASISTEMÁTICAS (MORALES) 0 INTRASISTEMÁTICAS (JURÍDICAS)?}

\section{Análisis de la sentencia C-083 de 1995}

La noción de principios puede sintetizarse en dos perspectivas que hemos llamado, de acuerdo con criterios como

12 Señala: "Artículo 4.-Los principios del derecho natural y las reglas de la jurisprudencia servirán para ilustrar la Constitución en casos dudosos. La doctrina constitucional es, a su vez, norma para interpretar las leyes". su naturaleza normativa y las funciones que desempeñan en el ordenamiento jurídico, fuerte y débil. Con fundamento en esos dos criterios, se puede representar el panorama colombiano en materia de principios de la siguiente manera:

Posición débil. Afirma que los principios no son normas jurídicas sino normas extra sistemáticas, morales, que están por fuera del derecho, que solo ejercen una función auxiliar frente a las normas jurídicas y que solo se aplican en los denominados casos difíciles. Son entendidos, principalmente, como principios de derecho natural. Entre uno de sus principales defensores se puede mencionar a Giorgio del Vecchio (1971, p. 113-125). En Colombia son ejemplos de esta posición el artículo 4 de la Ley 153 de 1887 y la Sentencia de la Corte Constitucional C-083 de 1995, magistrado ponente Carlos Gaviria Díaz.

Posición fuerte. Esta teoría fuerte de principios asume que forman parte del universo de las normas jurídicas junto con las reglas, en la medida en que son resultado de un proceso de inducción del mismo ordenamiento jurídico. Esta posición fuerte se puede clasificar, a su vez, en dos: una posición fuerte-débil que ve en los principios normas jurídicas, pero que solo ejercen funciones subsidiarias, como la de interpretar, integrar y crear derecho. Un ejemplo de esta posición es el texto del artículo 230 de la CP que los reconoce como criterios auxiliares; y la posición fuerte-fuerte, que señala que los principios son normas jurídicas que priman sobre las restantes normas del ordenamiento. 
Basta una sencilla observación de nuestra agreste realidad política y social para afirmar que la noción de principios que exige nuestro Estado social y constitucional de derecho es la fuerte-fuerte. Estas son las razones: 1. Los principios, como se indicó, son normas jurídicas, las más importantes del ordenamiento, que condicionan la validez de las restantes normas (argumento ontológico); 2. Los principios sirven de principal razón de la decisión o ratio decidendi de las sentencias de las altas cortes (argumento funcional); $y, 3$. Los principios prevalecen sobre las restantes normas por mandato del mismo legislador (argumento lógico), verbigracia, los artículos 13 del Código Penal $^{13}$, 26 del Código de Procedimiento Penal14 ${ }^{14} 21$ de la Ley 734 de $2002^{15}, 13$ de la Ley 836 de $2003^{16}$, 5 de la ley 1098 de

13 «Artículo 13. Normas rectoras y fuerza normativa. Las normas rectoras contenidas en este código constituyen la esencia y orientación del sistema penal. Prevalecen sobre las demás normas e informan su interpretación (subrayado fuera de texto).

14 «Artículo 26. Prevalencia. Las normas rectoras son obligatorias y prevalecen sobre cualquier otra disposición de éste código. Serán utilizadas como fuente de interpretación» (subrayado fuera de texto).

15 «Artículo 21. Aplicación de principios e integración normativa. En la aplicación del régimen disciplinario prevalecerán los principios rectores contenidos en esta ley y en la Constitución Política. En lo no previsto en esta ley se aplicarán los tratados internacionales sobre derechos humanos y los convenios internacionales de la OIT ratificados por Colombia, y lo dispuesto en los códigos Contencioso Administrativo, Penal, de Procedimiento Penal y de Procedimiento Civil en lo que no contravengan la naturaleza del derecho disciplinario» (subrayado fuera de texto

16 Artículo 13. Prevalencia de los principios rectores. En la interpretación y aplicación de este reglamento prevalecerán los principios rectores que determinan la Constitución Política, la Ley 734 de 2002 y la presente ley.
$2006^{17}, 16$ de la Ley 1123 de $2007^{18}, 3$ de la Ley 1306 de 2009'19, 197 numeral 9 de la Ley 1607 de $2012^{20}$.

Nos dedicaremos al estudio de la sentencia de la Corte Constitucional C-083 de 1995, M. P. Carlos Gaviria Díaz, en la

17 "ARTÍCULO 5. NATURALEZA DE LAS NORMAS CONTENIDAS EN ESTE CÓDIGO. Las normas sobre los niños, las niñas y los adolescentes, contenidas en este código, son de orden público, de carácter irrenunciable y los principios y reglas en ellas consagrados se aplicarán de preferencia a las disposiciones contenidas en otras leyes" (Subrayas extratexto)

18 Artículo 16. Aplicación de principios e integración normativa. En la aplicación del régimen disciplinario prevalecerán los principios rectores contenidos en la Constitución Política y en esta ley. En lo no previsto en este código se aplicarán los tratados internacionales sobre Derechos Humanos y deontología de los abogados, y lo dispuesto en los Códigos Disciplinario Único, Penal, de Procedimiento Penal y de Procedimiento Civil, en lo que no contravenga la naturaleza del derecho disciplinario. (subrayado fuera de texto).

19 Artículo 3. Principios: En la protección y garantía de los derechos de las personas con discapacidad mental se tomarán en cuenta los siguientes principios: a) El respeto de su dignidad, su autonomía individual, incluida la libertad de tomar las propias decisiones y su independencia; b) La no discriminación por razón de discapacidad; c) La participación e inclusión plenas y efectivas en la sociedad; d) El respeto por la diferencia y la aceptación de las personas con discapacidad mental como parte de la diversidad y la condición humana; e) La igualdad de oportunidades; f) La accesibilidad; g) La igualdad entre el hombre y la mujer con discapacidad mental; h) El respeto a la evolución de las facultades de los niños y las niñas con discapacidad mental y de su derecho a preservar su identidad. Estos principios tienen fuerza vinculante, prevaleciendo sobre las demás normas contenidas en esta Ley» (subrayado fuera de texto).

20 Artículo 197 numeral 9. APLICACIÓN DE PRINCIPIOS E INTEGRACIÓN NORMATIVA. En la aplicación del régimen sancionatorio prevalecerán los principios rectores contenidos en la Constitución Política y la ley. 
medida que se erige en el principal fundamento de la posición débil, con el objeto de determinar si dicha decisión guarda sintonía con el razonamiento jurídico exigido por el Estado social de derecho, si es armónica con otras sentencias sobre principios adoptadas por esa alta corporación y si es coherente con la misma doctrina citada.

Se procederá al análisis a partir de cuatro aspectos:

1. La enunciación de los principios como normas extra-sistemáticas con fundamento en aportes doctrinarios que, al mismo tiempo, defienden la idea de normas jurídicas que están dentro del ordenamiento.

Señala la Corte:

Según expresión afortunada de Carrió "pueden ser llamados "principios jurídicos" en cuanto se refieren a aquél (el derecho) pero no en cuanto parte de él"21 Y añade: "el uso judicial de ellos puede conferirles, en el mejor de los supuestos, el rango de candidatos a integrar el sistema, una vez que ese uso adquiera consistencia, regularidad y carácter normativo suficientes como para considerar que las pautas aplicadas son normas jurisprudenciales en vigor", o se incorporen al ordenamiento -agrega la Corte- por disposición del legislador.

${ }^{21}$ Estimamos que lo mismo se pude señalar respecto de los valores jurídicos: son jurídicos en cuanto hacen referencia al derecho, pero no como partes de él.
De la lectura a dos importantes textos de Genaro Carrió (Notas sobre derecho y lenguaje ${ }^{22}$ y Principios jurídicos y positivismo jurídico"23), se advierte que la Corte se refiere a los principios de derecho natural. Carrió señala que existen dos sentidos o nociones de principios: normas de segundo grado análogas a las reglas (normas de primer grado) que indican "cómo deben entenderse, aplicarse y, a veces, complementarse las reglas de primer grado" -a estos principios los llamo "Principios ${ }^{1224}-$; y como "objetivos, metas o policies de una regla o conjunto de reglas del sistema, ciertas exigencias fundamentales de justicia y moral positivas y ciertas máximas o piezas de sabiduría jurídica tradicional" -a estos principios los llamo "Principios-2"25-

Luego de esta distinción entre $\mathrm{P}^{1}$ y P2 , se da a la labor de determinar si ambos principios son derecho o normas jurídicas. Responde básicamente señalando que nada obsta para que los "Principios1" se consideren normas jurídicas, y los "Principios", que son normas morales, puedan ser partes del sistema a condición de que sean reductibles a "Principios1". Señala:

$$
\begin{aligned}
& \text { Con más generalidad, nada obsta } \\
& \text { a que sean reglas del sistema } \\
& \text { aquellas pautas de segundo nivel, } \\
& \text { primordialmente dirigidas a los } \\
& \text { jueces, que sirven para ajustar, }
\end{aligned}
$$

22 CARRIÓ, Genaro. Notas sobre derecho y lenguaje. 4. a ed. Buenos Aires: Abeledo Perrot, 1994. p. $225-$ 234.

23 Principios Jurídicos y positivismo jurídico. Buenos Aires: Abeledo-Perrot. 1970. pp. 57-74.

24 Notas sobre derecho...Op. cit., p. 214.

25 Notas sobre derecho... Ob. cit., p. 214. 
ampliar, restringir, etc., las reglas de primer nivel y exhiben un cierto grado de neutralidad tópica o indiferencia de contenido (Principios ${ }^{1}$. Nada obsta, además, a que sean reglas del sistema aquellas metas, objetivos, policies, exigencias de justicia, de equidad y de moral positivas que he llamado "Principios2", siempre que sean formulables como "Principios1", es decir, como reglas que poseen las características de éstos, o utilizables como standards del sistema. Los "Principios" ${ }^{1 "}$ (y los "Principios2" reducibles a ellos o utilizables como standards) que satisfacen los requisitos de la regla de reconocimiento son principios jurídicos en el sentido de que forman parte del derecho positivo como las restantes reglas del sistema. Para evitar confusiones los llamaré en adelante "principios de derecho positivo"26 (subraya fuera del texto).

Este autor, luego de aceptar la existencia de principios jurídicos, alude a otro tipo de principios que no satisfacen las condiciones de la regla de reconocimiento y que, por esa razón, no son normas jurídicas sino morales:

(vii) Principios jurídicos que no son partes del derecho. Los principios que no satisfacen los requisitos de la regla de reconocimiento -sean "Principios ${ }^{1 "}$ o "Principios2"- quedan fuera del derecho. No son "principios de derecho positivo": Pueden ser llamados "principios jurídicos" en cuanto se refieren a aquel, pero

26 Ib. p. 228. no en cuanto partes de él. El uso judicial de ellos puede conferirles, en el mejor de los supuestos, el rango de candidatos a integrar el sistema, una vez que ese uso adquiera consistencia, regularidad y carácter normativo suficientes como para considerar que las pautas aplicadas son normas jurisprudenciales en vigor" ${ }^{\prime 2}$.

Seguidamente expresa, en relación con la fuerza vinculante de los principios jurídicos o "Principios"1", lo siguiente:
Pues bien, las "exigencias" de al- gunos principios de derecho posi- tivo parecen más naturalmente concebibles al modo como son concebidos los "requerimientos" emanados de fuentes meramente permisivas. Esto no afecta el hecho incuestionable de que en todo sistema de derecho hay un núcleo central de reglas, estándar y principios cuya observancia es obligatoria 28 (subraya extra texto).

De las anteriores referencias se advierte con claridad que Carrió reconoce como partes del derecho los principios entendidos como normas de segundo grado que señalan la forma de aplicación de las reglas (normas de primer grado), y condiciona el carácter jurídico de los principios entendidos como criterios de justicia o pautas morales a su correspondencia con los principios de derecho positivo. En síntesis, Carrió, desde el positivismo, reconoce tres aspectos fundamentales para la teoría de principios jurídicos: el

\footnotetext{
27 Ib. p. 229

28 Ib. P. 231.
} 
primero, que son normas jurídicas; el segundo, que su observancia es obligatoria $\mathrm{y}$, el tercero, que sirven para restringir las normas de primer nivel o reglas.

De una contrastación entre el pensamiento de Carrió y lo señalado por la Corte en la sentencia sometida a análisis que indica que los principios generales del derecho son normas extra sistemáticas, se puede concluir que el máximo tribunal en lo constitucional alude solo a una noción de principios defendida por ese autor (Principios que no son partes del derecho o $\mathrm{P}^{2}$ ) desconociendo la existencia de otro tipo de principios jurídicos que pertenecen al ordenamiento jurídico llamados principios generales del derecho o P1. Por respeto al pensamiento de Carrió y al razonamiento jurídico que impone el Estado social de derecho, la Corte Constitucional debió entender la expresión "principios generales del derecho" en el artículo 230, como una alusión a principios jurídicos y no a principios de derecho natural.

Para finalizar este acápite, resulta extraña la adscripción de la Corte a la idea de principios de derecho natural, cuando en la misma sentencia sometida a análisis cita las ideas de Joaquín Arce y Flórez-Valdés para quien los principios son criterios de validez y súper fuente del derecho. Señala:

[...] Y cabe, asimismo, sostener que los principios generales ya no son mera fuente supletoria, cuya aplicación necesite la doble prueba de ausencia de ley y carencia de costumbre, como antaño vino a exigir nuestra jurisprudencia, aunque de modo innecesario. Los principios generales son ahora una fuente supletoria, desde luego; pero, principalmente, una fuente material básica y primaria de nuestro ordenamiento jurídico, capaz de adquirir primacía, en un puro orden jerárquico, sobre la ley y la costumbre; con virtualidad para matizarlas, con fuerza para generarlas, con potencialidad para invalidarlas. Son, en definitiva, una "súper-fuente", por cuanto pueden ser fuente de las mismas fuentes ${ }^{29}$.

A modo de conclusión, se advierte una irregular citación de las fuentes doctrinales por parte de la Corte Constitucional, lo que obliga a que, si se desea guardar coherencia con ellas y respeto por el Estado social, se entienda la expresión "principios generales del derecho" en el artículo 230 como una referencia a normas jurídicas y no a normas de derecho natural. En este mismo sentido, señala el profesor Valencia Restrepo (2007, p. 514), desde una perspectiva no positivista, que los principios deben ser entendidos como normas jurídicas.

2. La adscripción de los principios al grupo de "fuentes jurídicas permisivas" entendiendo por ello que "no es obligatorio para el juez observar las pautas que de ellas se desprende".

La Corte Constitucional señala como funciones de los principios interpretar e integrar el ordenamiento. Cuando ejercen la función interpretativa se inscriben den-

29 Arce y Flórez-Valdés. Los principios generales del derecho y su formulación constitucional. Madrid, Civitas, 1990, p. 55. 
tro de las llamadas fuentes jurídicas permisivas, esto es, como "criterios auxiliares de la actividad judicial" tal como lo señala el artículo 230 de la C. P. Ese carácter de fuente permisiva es consecuencia lógica de la asunción de los principios como normas extra sistemáticas, de derecho natural o "Principios P2", en términos de Carrió. No obstante, se debe insistir en que no es posible comprender la función de los principios a partir de una exégesis del texto del artículo 230 que señala que son "criterios auxiliares". Es cierto que cuando los principios jurídicos ejercen una función interpretativa se insertan dentro de las fuentes permisivas, pero si se tiene en cuenta su naturaleza jurídica y su posición frente a las reglas, resaltan otras funciones como la fundamentadora de derechos fundamentales, la de límites al ejercicio del poder y la validadora de las restantes normas del ordenamiento jurídico. En consecuencia, ya no se trata de una fuente permisiva sino de una fuente obligatoria.

\section{La Corte afirma que los principios no son} normas que pertenecen al ordenamiento y los equipara a la equidad y al derecho natural, haciendo así referencia no a los principios jurídicos sino a los principios morales de tinte dworkiano. Pero esta idea según la cual los principios no son normas jurídicas es opuesta a la sostenida, por ejemplo, en la sentencia C-067 de 2003, en la que, con apoyo en la doctrina de Norberto Bobbio ${ }^{30}$, reconoce a las normas que forman parte del bloque de constitu-

$30 \quad$ Así es la cita de la Corte Constitucional del texto de Bobbio: Principi Generali del diritto. NDI (Novíssimo Digesto Italiano), XIII, UTET, Torino, p. 887. cionalidad las mismas funciones de los principios generales del derecho, esto es, confiere a los principios constitucionales las mismas tareas a cargo de los principios jurídicos. Señala la Corte:

Las normas del bloque operan como disposiciones básicas que reflejan los valores y principios fundacionales del Estado y también regulan la producción de las demás normas del ordenamiento doméstico. Dado el rango constitucional que les confiere la carta, las disposiciones que integran el bloque superior cumplen la cuádruple finalidad que les asigna Bobbio, a saber, servir de i) regla de interpretación respecto de la dudas que puedan suscitarse al momento de su aplicación; ii) la de integrar la normatividad cuando no exista norma directamente aplicable al caso; iii) la de orientar las funciones del operador jurídico, y iv) la de limitar la validez de las regulaciones subordinadas.

En otro texto ${ }^{31}$ expresamos que la función señalada bajo el numeral iv (limitación de la validez de las normas infraconstitucionales) remite al concepto de validez material que predica la necesaria coherencia de las normas con los contenidos axiológicojurídicos del ordenamiento ${ }^{32}$, cualificando

${ }^{31}$ Los principios Jurídicos y el bloque de constitucionalidad. 2. a ed. Universidad de Medellín, 2011.p. 97.

32 La Corte Constitucional expresa no solo con claridad sino con imperatividad el necesario sometimiento de las normas a los principios, lo que impone su lógica incorporación al Bloque de la Constitucionalidad. Así, en sentencia C-479 de 1992. M.P. José Gregorio Hernández Galindo y Alejandro Martínez Caballero, señaló con referencia a la obligatoriedad del preámbulo de la Constitución "Las normas pertenecientes a las demás jerarquías del sistema jurídico están sujetas a toda la cons- 
así el concepto de validez formal. Se podría afirmar que, si las normas pertenecientes al bloque determinan la validez de las restantes del ordenamiento, los principios, al servir de parámetros de validez material de las restantes normas, pueden ser estimados como integrantes del bloque de constitucionalidad".

\section{El desconocimiento de la voluntad del} constituyente de hacer de los principios límites de hierro al ejercicio del poder político.

Quienes conocieron o se han familiarizado con el proceso constituyente de 1991

titución y, si no pueden contravenir los mandatos contenidos en su articulado, menos aún les está permitida la transgresión de las bases sobre las cuales se soportan y a cuyas finalidades apuntan". Hace propias las palabras del Magistrado Luis Carlos Sáchica, ex miembro de la entonces Sala Constitucional de la Corte Suprema de Justicia, quien señaló en salvamento de voto del 2 de octubre de 1980 "Si se quiere, por otra parte, vivificar la Constitución, ello exige entender que ella no solo está conformada por las normas positivas en que se expresa, sino por los principios implícitos en las mismas y por los valores enunciados como objetivo de su preceptiva; estas son instancias supra, aunque no extraconstitucionales, a las cuales es necesario referir toda interpretación y aplicación de las normas positivas y su desconocimiento debe acarrear invalidez, inconstitucionalidad, pues todo lo que sea contrario a la justicia, tiene que ser contrario al derecho, y un control de constitucionalidad que no tenga este enfoque es incompleto y carece de eficacia. En consecuencia, cuando las normas acusadas, no importa su rango, atentan contra la unidad nacional, la paz o la justicia, proclamadas en el Preámbulo de la Constitución como razón de ser de la forma de vida colectiva en ella propuesta, el juez de constitucionalidad debe invalidarlas, ya que el derecho positivo no se justifica por sí mismo" (Sentencia de octubre 2 de 1980. Jurisprudencia y Doctrina. Tomo X. Revista N. ${ }^{\circ}$ 109). Y en sentencia C-957 de 1999 M. P. Álvaro Tafur Galvis, expresó la Corte Constitucional "Una norma contraria a los principios y valores constitucionales no es válida". deben recordar los problemas de sistematización normativa existentes al momento de la expedición de la Constitución Políti$\mathrm{ca}^{33}$, y ayudan a reconocer que la norma de normas no puede ser considerada una norma perfecta. Existen antinomias, cláusulas vagas y normas materialmente constitucionales cuya incorporación no era posible en el texto de la Constitución.

En otro escrito ${ }^{34}$, resultado de investigación, se resaltaron dos problemas al momento de determinar el sentido de la expresión "principios generales del derecho". El primero, la polisemia, esto es, diferentes términos para referirse a un mismo elemento; el segundo, la inexistencia de un debate teórico en relación con la noción de principios que debía adoptarse en el Estado social de derecho:
Expresiones como principios políticos, principios jurídicos, principios generales del derecho, principios del derecho natural, son empleadas por el constituy- ente, sin que se pueda determinar el significado de las mismas y me- nos su función dentro del sistema político y el ordenamiento ju- rídico. La ausencia de un debate constituyente con relación a su significado y uso ha promovido una inercia frente a los principios cuando al día de hoy se afirman no solo como paradigmas del sistema constitucional a la luz

33 De la expectativa al desconcierto. El proceso constituyente de 1991 visto por sus protagonistas. Ricardo Zuluaga Gil, Pontificia Universidad Javeriana, 2008, p. 132.

34 El neoconstitucionalismo principialista en la Asamblea Nacional Constituyente de 1991. Revista prolegómenos.pp.27-42, 2014 
de las diferentes concepciones neoconstitucionalistas sino como las principales herramientas jurídicas para limitar el ejercicio del poder ${ }^{35}$.

A pesar de las diferentes nociones empleadas frente a los principios y los escasos debates en relación con su naturaleza y funciones en el Estado social, es necesario recordar que existía una voluntad clara de incorporarlos a modo de límites al ejercicio del poder punitivo y como herramientas para el mejoramiento de la función jurisdiccional. Así, el exconstituyente Hernando Londoño Jiménez expresó, en alusión a los principios, que en la «Constitución Nacional deben consagrarse unos límites de hierro a las tentativas totalitarias» y que estos fungen de «límites constitucionales que se impondrían a la elaboración dogmática del hecho punible y de la política criminal del Estado"36

En ese mismo sentido, merecen ser resaltadas las palabras del presidente de la Asamblea, Álvaro Gómez Hurtado, en las que se menciona la función de los principios como límites al ejercicio de la discrecionalidad judicial:

Hemos aprobado principios jurídicos que no solo hacen más eficaz la administración de justicia, sino que la vuelven confiable, porque con ellos impediremos sus desmanes (Gómez, 1991, p. 35).

35 Ib. P. 38

36 Londoño, 1991, p. 30.
Difícil encontrar alguna razón que ayude a comprender por qué la Corte Constitucional adoptó una noción de principios como normas extra sistemáticas cuando el constituyente fue claro al señalar que ellos serían límites al ejercicio del poder. Se puede afirmar que esa decisión fue resultado de un ejercicio de teoría y filosofía del derecho al margen del contexto social y político, en el que primó más la racionalidad que la razonabilidad.

A modo de conclusión, se puede señalar que el carácter auxiliar de los principios consagrados en el artículo 230 de la C. P. y su idea de normas extra sistemáticas no puede representar la negación de principios jurídicos intra sistemáticos cuyas funciones van más allá de las tradicionalmente consideradas como auxiliares (interpretativa, integrativa y creativa), en la medida que en el Estado social de derecho fungen de criterios de validez material de las restantes normas del ordenamiento, fundamento de los derechos fundamentales, concreción de los valores jurídicos y límites al ejercicio del poder.

4. De principios jurídicos prevalentes a normas extra-sistemáticas. El desconocimiento de la sentencia T-406 de 1992

A pocos meses de entrada en vigencia la Constitución Política de 1991, la Corte Constitucional profirió una de las decisiones más importantes para la cultura constitucional: la sentencia T-406 de 1992. En ella se explicó la noción de Estado social de derecho, los cambios en el razonamiento jurídico con el ingreso de ese 
modelo político, los criterios de determinación de los derechos fundamentales y la naturaleza y funciones de los principios constitucionales y los valores.

Señala que los principios son normas jurídicas "dotados de toda la fuerza normativa que les otorga el artículo cuarto del texto fundamental" y ante la pérdida de la capacidad regulatoria de la ley "adquieren importancia excepcional" a pesar de que en el pasado fueron considerados secundarios dentro del sistema de fuentes.

Es cierto que la Corte Constitucional se refiere a los principios constitucionales, pero una aproximación a su naturaleza y funciones en el Estado social de derecho permite afirmar que resulta complejo, por no decir imposible, establecer diferencias entre los principios constitucionales y los no constitucionales. Solo un criterio topográfico de corte formalista permitiría afirmar que los principios constitucionales son los que están en el texto de la Constitución y los no constitucionales los que están por fuera del mismo.

Tanto los principios que están en el texto de la Constitución Política como los consagrados por el legislador son normas prevalentes que determinan la validez material de las restantes normas del ordenamiento jurídico. Resulta imposible determinar diferencias ontológicas entre los principios que están en el texto de la Constitución y aquellos que no lograron su consagración en la norma de normas. Es claro que en la Constitución no están todas las normas constitucionales ni todo lo que está en ella tiene el mérito jurídico suficiente para ser parte del cuerpo de normas prevalentes.

Un ejemplo ayudará a una mayor comprensión. El principio de la prevalencia del derecho sustancial sobre el formal (artículo 228) es un principio, otrora, consagrado en diferentes codificaciones infra-constitucionales. El constituyente de 1991 lo elevó a rango constitucional sin que ello signifique que haya adquirido una mayor importancia frente a aquellos principios que no lograron su incorporación en el texto de la norma de normas. Igual ocurrió con un sinnúmero de principios del derecho laboral, de la seguridad social, del derecho ambiental, del derecho penal, del derecho administrativo, del derecho tributario, que antes estaban en un rango legal, pero que luego ascendieron al rango de normas constitucionales.

Resulta complejo afirmar que solo los principios que están en el texto de la Constitución son normas prevalentes. Una situación librada al albur o a la voluntad del constituyente no puede fungir de criterio para determinar la importancia de un principio o su naturaleza constitucional. Todos los principios jurídicos, al margen de su ubicación o jerarquía en el ordenamiento jurídico, son normas que fundamentan derechos fundamentales, determinan la validez de las restantes normas del ordenamiento y sirven para limitar el ejercicio del poder.

En síntesis, resulta difícil comprender las razones por las cuales la Corte Constitucional se apartó del precedente establecido en la sentencia T-406 en la que 
se reconoció la importancia excepcional de los principios y pasó a señalar que los mismos eran normas extra-sistemáticas.

\section{CONCLUSIONES}

Del estudio a la sentencia C-083 de 1995, se pueden formular las siguientes inferencias:

- Al interpretar la expresión "principios generales del derecho" en el artículo 230 de la C. P., la Corte Constitucional optó por una noción de principios como normas extra-sistemáticas que poco favor presta a la incorporación y aplicación directa de los principios jurídicos, desestimando su carácter de normas jurídicas que cumplen una función validadora, legitimadora y fundamentadora de derechos fundamentales.

- A partir de criterios como su naturaleza (jurídica) y funciones dentro del ordenamiento jurídico (fundamento de derechos fundamentales, criterios de validez material de las restantes normas del ordenamiento, concreción de valores, límites al ejercicio del poder, principal razón de la decisión en las sentencias de las altas cortes), es posible sostener que todos los principios integran el bloque de constitucionalidad.

- No es posible comprender la naturaleza y funciones de los principios en el Estado social de derecho a partir de la sola lectura de la sentencia C-083 de 1995. Existen decisiones (T-406 de 1992, C-067 de 2003) en las que se indica que son normas jurídicas que fundamentan la validez de las restantes normas del ordenamiento y permiten justificar su incorporación al bloque de constitucionalidad.

- Si todos los principios son, desde un punto de vista racional, resultado de un proceso generalizador inductivo (analogía iuris), resulta difícil establecer diferencias entre los principios constitucionales y los principios infraconstitucionales a partir de un criterio jerárquico o formal soportado en su consagración o no en el texto de la Constitución o de la ley.

- La expresión principios generales del derecho es ambigua y se refiere a dos nociones: principios de derecho natural y principios jurídicos o de derecho positivo. De las dos, la que más se ajusta a los fines del Estado social es la segunda en tanto que los asume como normas prevalentes sobre las restantes del ordenamiento, fundamento de derechos fundamentales y límites al ejercicio del poder.

- La Corte debe, en aras de facilitar el ejercicio de la función jurisdiccional, expedir una sentencia de unificación en la que se señalen las diferentes nociones de principios y su función en el Estado constitucional y social de derecho colombiano. Asumir, tal como lo indica la sentencia C-083 de 1995, que los principios son normas extrasistemáticas sería desconocer no solo su naturaleza o carácter jurídico, sino la 
condición de criterios de validez de las restantes normas del ordenamiento.

- Existen razones suficientes para afirmar que en el Estado constitucional no es posible confundir los principios jurídicos con los principios de derecho natural. No puede ser parte del derecho natural el conjunto de principios rectores de cada área del derecho que el mismo legislador considera prevalentes sobre las restantes normas, menos cuando se erigen en principal argumento de decisión (ratio) en la jurisprudencia de las altas cortes, límites de hierro al ejercicio del poder, fundamento de los derechos fundamentales y criterios de validez material.

- La noción de principios como normas de derecho natural o extra-sistemáticas lacera la función de los principios jurídicos como criterios de determinación de la validez material de las restantes normas del ordenamiento jurídico y no es coherente con la voluntad del constituyente en la medida que este quería hacer de los principios jurídicos límites de hierro al ejercicio del poder y criterios de control de la actividad jurisdiccional.

Según lo expuesto, son muchas las tareas que debe asumir la comunidad jurídica con miras a la promoción de los principios jurídicos entendidos como principal paradigma normativo en el Estado social de derecho: la Corte Constitucional, unificando la jurisprudencia en relación con los principios jurídicos; los académicos realizando más investigación sobre el tema a la luz del contexto colombiano; las instituciones de Educación Superior, promoviendo la enseñanza de la principialística, y los jueces, superando el temor al prevaricato en la aplicación de los principios.

\section{BIBLIOGRAFÍA}

ARCE Y FLÓREZ-VALDÉS. Joaquín. (1990) Los principios generales del derecho y su formulación constitucional. Madrid: Civitas.

BERNAL, Carlos. (1997) El juez ordinario entre legalidad y constitucionalidad. Bogotá: Instituto de Estudios Constitucionales Carlos Restrepo Piedrahita.

BIDART, German. (1987). La interpretación y el control constitucionales en la Jurisdicción constitucional. Buenos Aires: Ed. Ediar.

CARRIÓ, Genaro (1994). Notas sobre derecho y lenguaje. 4. ${ }^{\mathrm{a}}$ ed. Buenos Aires: Abeledo Perrot.

. Principios jurídicos y positivismo jurídico. (1970) Buenos Aires: AbeledoPerrot.

ESTRADA, Sergio (2011) Los principios Jurídicos y el bloque de constitucionalidad. 2. a ed. Medellín: Universidad de Medellín.

FERRAJOLI, Luigi. (2008) La teoría del derecho en el sistema de los saberes jurídicos En La teoría del derecho en el paradigma constitucional. Madrid: Fundación coloquio jurídico europeo, 2008.

GASCÓN, Marina (1997). Fuentes del derecho. En Lecciones de Teoría del Derecho. Jerónimo Betegón Carrillo y otros. Madrid: McGrawHill.

GUASTINI, Riccardo. (1999) Distinguiendo. Estudios de teoría y metateoría del derecho. Trad. Jordi Ferrer i Beltrán. Barcelona: Gedisa. 
HÄBERLE, Peter. (2007) El Estado constitucional. Trad. Héctor Fix Fierro. Buenos Aires: Astrea

HABERMAS, Jürgen. (1998) Facticidad y validez, Trad. Manuel Jiménez Redondo, Madrid: Trotta.

PERELMAN, Chaim. (1979) La lógica jurídica y la nueva retórica. Trad. Luis Díez-Picazo. Madrid: Civitas

. El neoconstitucionalismo principialista en la Asamblea Nacional Constituyente de 1991. Revista prolegómenos, 2014.
VALENCIA, Hernán. (2007) Nomoárquica, principialistica jurídica o filosofía y ciencia de los principios generales del derecho. $4{ }^{\mathrm{a}}$ ed. Medellín: Comlibros.

ZULUAGA, Ricardo. (2008) De la expectativa al desconcierto. El proceso constituyente de 1991 visto por sus protagonistas. Cali: Pontificia Universidad Javeriana. 